\title{
Design of Cooperative Learning Activity Based on Future Classroom*
}

\author{
Wang Zhou-xiu \\ Nantong University, Nantong, China
}

\author{
Qiu Tian \\ East China Normal University, Shanghai, China
}

\begin{abstract}
As a new kind of learning spaces, future classroom which integrates multiple technologies has been attracted more and more researchers in recent years. Cooperative learning, as a classroom organizing form, has more probability in the environment of future classroom. This research, by means of literature analysis, defines the concepts of future classroom and cooperative learning, discusses how future classroom environment supports cooperative learning, and analyzes the elements of learning activity system. Based on it, this paper constructs the model of cooperative learning in the future classroom.
\end{abstract}

Keywords: future classroom, cooperative learning, learning activity design

\section{Introduction}

In recent years, with the rapid development of science and technology, cloud computing, Internet of things, wireless network coverage, and touch and multi-display, all of these technologies have brought new opportunities to education. Researchers are beginning to study how to apply these technologies in the classroom to improve the quality of teaching, which prompted educational researchers to turn to research the new learning space. Thus, as a new kind of learning spaces, future classroom, which integrates multiple technologies, has been attracted more and more researchers in recent years.

From abroad, the study of future classroom has got the attention of the government, enterprises, and schools. More typical research including the plan of "Apple Classroom of Tomorrow" (ACOT) which was started in the 1980s by Apple (ACOT, 2013), the project of Massachusetts Institute of Technology Technology Enabled Active Learning (MIT TEAL) (MIT, 2013) which was carried out since 2000 by the MIT, and so on, performed a set of explorations from both theory and practical application. Domestically, it has had a series of results after three years of development since the first time to officially define the concept of "future classroom" in 2010 (Zhang \& Chen, 2010). Zhang and Chen (2010) elaborated on the positioning and characteristics of the future classroom. Gao, Chen, and Zhang (2009) put forward the design principle of the future classroom. Xu, Wang, and Ma (2013) probed into the design framework of future classroom. Chen (2011) expounded the concept, features, design, and corresponding teaching mode of future classroom from the perspective of educational technology in his doctoral dissertation "Research on the Future Classroom From the Perspective of Educational Technology." However, throughout the domestic studies about future classroom, it

\footnotetext{
*Acknowledgment: This paper was supported by Modern Educational Technology Research Project of Jiangsu Province (No. 2015-R-40624).

Wang Zhou-xiu, M.A., associate professor, Department of Education Technology, Nantong University.

Qiu Tian, M.A. candidate, Department of Education Technology, East China Normal University.
} 
is rare for practical application and evaluation. Most of them are still largely focused on proposal of the concept, architecture of the classroom, and designing of the teaching mode. Chen (2011) put forward the structure of the future classroom teaching model in his doctoral dissertation which was used to show ideas and operational processes about how to make use of the environment and the characteristics of the activities provided by the future classroom to processes lessons, classes, and after-school integrated design. On this basis, he designed the two application cases, but its application effect was not analyzed and evaluated. In addition, the three characteristics of teaching structures in future classroom including multi-dimensionality, hierarchy, and interactivity were discussed in "Study on the Teaching Structures in the Classroom of the Future" by Gao (2012), which was not applied to practical application either.

Implementing the application level is essential necessary to explore future classroom. However, the application layer of the study is inseparable from the teaching in the classroom. "Collaboration" is one of the core concepts of future classroom, and cooperative learning is one of the typical learning methods to support and promote collaboration. Therefore, in the case of focusing on cooperative learning activity design in future classroom, this article will carry out some research on design, application, analysis, and evaluation of cooperative learning activity practice case and try to provide reference for further application and promotion.

\section{Future Classroom and Cooperative Learning}

\section{Future Classroom}

In Christensen, Horn, and Johnson's (2008) book, Disrupting Class: How Disruptive Innovation Will Change the Way the World Learns, students are encouraged to plan work together and share the achievements in future classroom rather than simply memorize some information. Gao et al. (2009) thought:

The design of future classroom should be student-centered. In addition to meet a variety of different forms of knowledge communication, comfort, convenience, and humanization are also important factors to be considered. And, we need to design the future classroom, just like design a car. (p. 15)

Chen and Zhang (2010) said:

Future classroom is an environment and activity for teaching and learning absorbing the essence of humanism, interaction, environmental psychology, and other related theories, in which the function of component elements of classroom (people, technology, resources, environment and methods, etc.) are exerted with the aid of the intelligent information, artificial intelligence, and other technical support to implement teaching and learning, so as to promote the learning and development of human's cognition, skills, and emotions. (p. 24)

On the combination of the views, although the concept was defined by different researchers from different perspectives with taking environmental elements in the future classroom, but they all emphasized "collaboration." And in such an environment, a variety of teaching and learning activities are accessible to teachers and students. Students can learn by multiple channels to improve the efficiency. It mainly reflects in:

1. The overall environment of the future classroom is intelligent, concise, and comfortable. It needs suitable temperature and light and appropriate color of the walls, tables, and chairs. Students could be calm, so as to fall into learning state easily and classroom managers could achieve the whole equipment management only with the simple operation.

2. The teaching context of future classroom is more systematical, convenient, and reliable, including the technology of cloud computing operating system, multi-display, and wireless network coverage, which can 
provide support for the whole process of teaching and learning and play an important role in improving the students' abilities. Student can carry out a series of learning process from initial preparation to data collection until review after class. Teachers are allowed to conduct a series of teaching progress from the initial lessons preparing to eventually teaching reflection.

3. It is conducive to on-campus and off-campus learning and formal and informal learning, so that students could not only learn during the class time, but also review and rethink by learning supporting system after class.

\section{Cooperative Learning}

The research of cooperative learning can be traced back to more than half a century. During the intelligence-based warfare in the Second World War, cooperative learning has been found to complete the task that separate individuals are unable to do, and a number of researchers have begun to study it what becomes an increasingly valued issue for school education in more than half a century. It became popular in the United States in 1970s of the 20th century and brought heats quickly about within the scope of world. A. K. Ellis, who is a famous education critics from America pointed out that "either cooperative learning is the largest educational in modern world or one of the largest at least" (Ellis, 2005). A conclusion getting from studying a couple of practical cases by Johnson brothers showed cooperative learning has more advantages and effects than individual learning and competitive learning (Johnson, Johnson, \& Stanne, 2000).

For the definition of cooperative learning, different researchers have different views, and some scholars also conduct in-depth analysis on the related concepts including collaborative learning, group learning and learning community. According to Johnson et al. (2000), there are five basic elements of cooperative learning: positive interdependence, face-to-face interaction, individual accountability, group processing, and interpersonal and small group skills (David, 2004). Chinese scholar named Sheng Qunli made a comparative analysis on the collaborative learning and traditional learning, and he pointed out that students have higher participating in collaborative learning (Sheng, 2006). In terms of learning goals, the academic objective is as important as social interaction objective. For the learning context, different students are responsible for different parts. The organizational form mostly emphasizes positive interdependence and stresses on group learning accompanied by class teaching at the same time. Besides, the unification of multi-lateral interaction methods between teachers and students or students and students or teachers and teachers is also a most important factor (Sheng, 2006). On the basis of the research on cooperative learning by Wang (2002), it is proposed six basic ideas that consist of interaction view, target view, teacher-and-student view, form view, evaluation view along with view of instance.

Combining with the above scholars' point of view, the authors of this paper consider that cooperative learning means two people make good use of their talents to finish a common task and realize mutual benefit and win-win progress. It possesses the following characteristics: specific goals, reasonable grouping, clear responsibility, positive interdependence, diversified interaction, appropriate reflection, and scientific evaluation.

\section{The Support of Future Classroom for Cooperative Learning Activity}

There are several factors affecting cooperative learning from previous literature (Jiang, 2009). Among them, the key factor of its success, including environment, interaction, circumstances setting (meaning 
construction), and evaluation, could be promoted or improved by future classroom with the support of space environment and technology.

\section{Providing Barrier-Free Learning Space}

Learning space is a place where learning takes place. It not only includes the study of outer space, including learners' individual space of inner change. And, whether the learning approaches are clear will directly influence students' learning efficiency. From the external channels, flexible and movable desk and chair in future classroom can support different size group and different forms (role plays, debates, and jigsaw method) cooperative activities. Teachers are no longer in the front of the classroom and bound to the platform, but are free to shuttle between different groups to provide activity guide. From the internal channels, it is a favorable environment which has appropriate illumination, temperature, and overall tone and excellent amplification equipment that can help learners clear the obstacles of sensory channel, such as vision, hearing, and touch. So, the attention of students will not be scattered. Further, high-definition remote interactive system takes learning out of classroom and provides more opportunities for students to interact with outside.

\section{Promoting Positive Interaction of Cooperation}

Taking part in the classroom plays a very significant role in stimulating students' study motive, raising the efficiency, and building up power to learning. An effective approach of promoting team members to participate in the cooperation is to add some interactive activities into it. In future classroom, wireless network coverage, mobile terminal, and multi-display lay a solider foundation to interaction. Students are connected by the network and they can project learning outcomes to the screen without affecting the classroom order to make the discussion more available. With the support of such environment, it is easy to realize "interaction between man and man, man and environment interaction, interaction between people and resources, human and technical (equipment) interaction" (Chen, Ye, Qin, \& Zhang, 2011).

\section{Creating Rich Situation to Promote the Meaning Construction}

From the view of learning characteristics, cooperative learning can be divided into inquiry-based learning, problem-based learning, project-based learning, etc.. All of these learning activities need learners who face the tasks and problems which may be situational and ill-structured to construct new meaning on the basis of their own experience. According to some scholars, knowledge construction needs to provide a rich "supplies" for learners, such as technical maintenance, social provision, and educational supplies, including a wealth of learning resources and learning tools and the construction of diversified learning activity, so that students can construct individual knowledge and collaborative knowledge effectively (Wang \& Zhong, 2008). In addition, students can gather information prepared by teachers through the platform of future classroom which provides learners abundant learning resources, and carry out further study. Furthermore, rich media environment provides a full range of support for teachers to set up circumstance, impart knowledge, and let resource to be the biggest value to promote open learning.

\section{Immediate Feedback, Promoting Reflection}

Instant feedback and accurate evaluation are conducive to students' self-awareness and progress. The feedback system of future classroom can promote convenient and effective communication between teacher and students, at the same time, to rapid response to the problems of students. And, future classroom is a quiet 
and intimate environment for personal reflection using the screen, a "soft partition" (Xu et al., 2013), to form a relative privacy of the individual space where the cooperative learning can be commenced smoothly. It can avoid the influence caused by big noise between groups. Besides, intelligent records and broadcasts system can provide supervision and observation learning to further promote reflection.

\section{The Design of Cooperative Learning Activity Based on Future Classroom}

The comprehension of Hamlet varies from reader to reader. So does the dreams of the future. As far as domestic and foreign researchers, the expressions of future classroom are various but the basic ideas are consistent. They all emphasized people-oriented, interaction, participation, etc. (Xu \& Zhang, 2013) to realize the true knowledge of class and life.

Conducted by these theories, researchers have explored the different classroom environments to support different types of learning activity. Below, this paper will expound the elements and organizational process of cooperative learning for how future classroom environment provide support, and point out its organizational process design mode on this basis.

\section{Elements of Cooperative Learning Activity}

Teaching design of learning activity is an important step, which determines whether a student is able to receive teacher's learning content and motivated to study harder. Founded on the activity theory (Engeström, 2001), an important role of the study of human activities which is used to design learning activity, Chinese scholars Yang Kaicheng provided a comprehensive analysis of the system and put forward the elements of the learning activity: learners, learning goals, learning community, the rules of learning community, division of tasks, and learning tools (Yang, 2005). As a kind of organization form of learning activity, the design of cooperation needs to follow the principle of the general design of learning activity and exhibits its specific characteristics. Refer to the classification, this research identified and developed some previous definitions of cooperative learning activity and produced the elements that including cooperation, collaboration object (learning objectives), the cooperative community, collaboration rules, and division of collaboration and learning support, as shown in Figure 1.

For collaborative learning, all of these elements for learners are devote to achieving the expected goals, realizing the meaning construction of knowledge and getting good emotional experience.

In cooperative learning activity, the learning objective which fits the cooperation's cognitive level and relates to the actual needs determines the activities in the right direction. In addition to, a fair and orderly cooperation whose premise is collaboration rules can make partner develop their personality and special skills and maximize system of function. And, the learning support is a strong assurance that learning subject can overcome the obstacle to promote cooperative development. As for the cooperative community, it is a higher level of cooperation that different cooperation subjects can learn from each other, common progress, and achieve leaning goals. To sum up, in the cooperative learning activity system, with cooperation as the core, collaboration rule is the premise and learning goal is direction. Meanwhile, with the collaboration division of the tasks as project, learning support is safeguard and cooperative is sublimation. Thus, the future classroom is expected to maximize elements of function in with the help of technology, method, and emotion. 


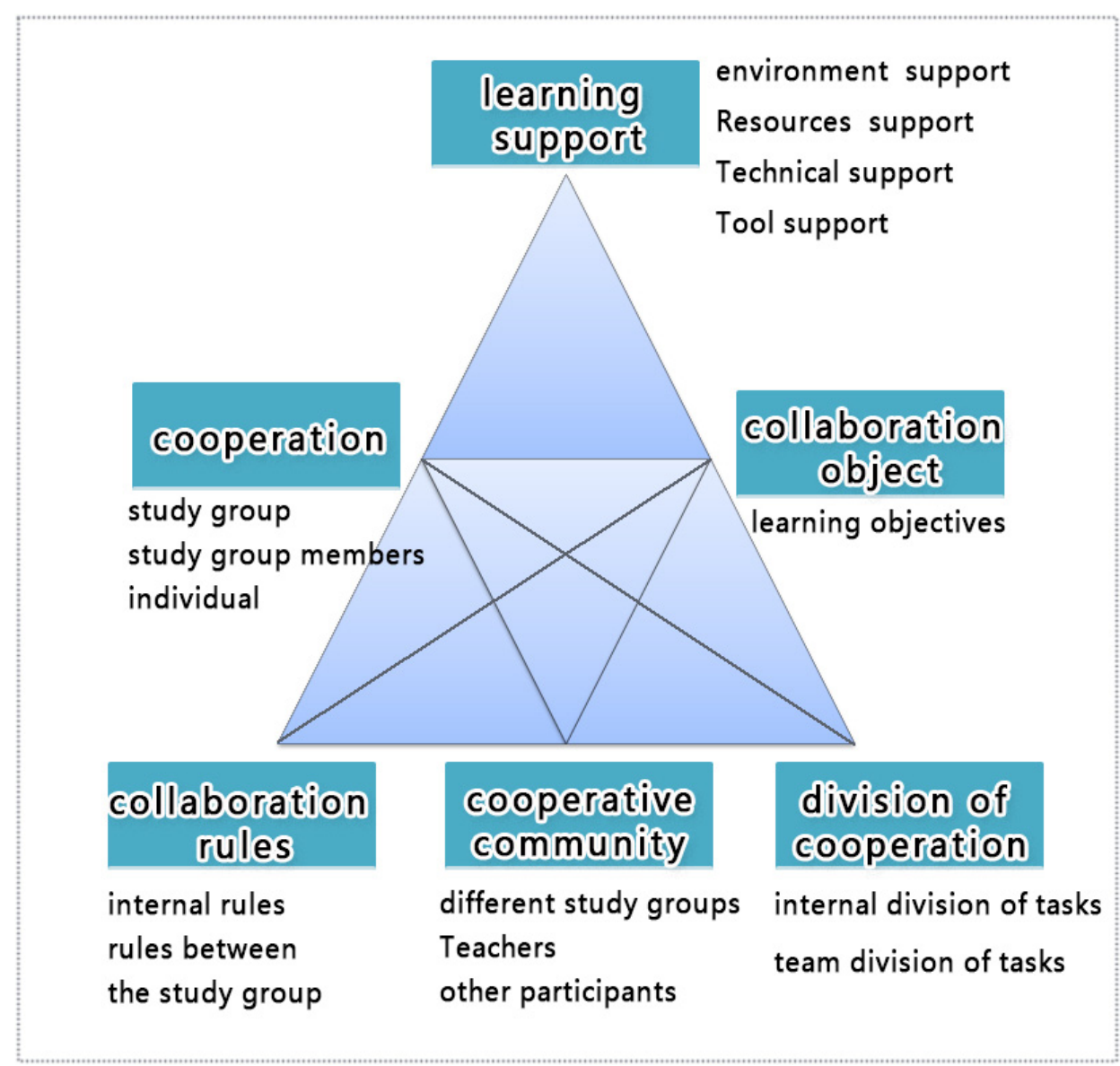

Figure 1. The elements of cooperative learning activities.

\section{Organization of Cooperative Learning Activity}

The element of organization of cooperative learning activity is investigated both grouped and organized.

When it comes to forming a cooperative learning group, learners can be divided into groups of two, three, four, or even ten according to the different cooperation activities' needs. On the basis of previous research, Chen (2003) pointed out in "Organizational Development for a Team-based Cooperative Learning" that a group of four to six people is a general choice to achieve the best results in the effectiveness and participation. From practice level, students are divided into six groups in Du Langkou Middle School by the difference class size. Some groups have six to seven people, and some teams have about 10 (Cui \& Xie, 2009). But, in Tianjin Middle School, two students study as a small group (deskmates), and a large group composed of these small groups. United States scholars Johnson et al. (2000) who have long-term study of cooperative learning summarized on the group scale. They pointed out that the smaller cooperative learning groups, the better the implementation of cooperative learning and task. In general, most researchers showed that cooperative learning groups depend on the nature of learning, class size, and the amount of resources allocated dynamically. Therefore, at the back of the case design, the size of learning groups are confirmed as four according learning content and learning conditions, etc.. In addition, characteristics of students and roles of team members match also should be considered when grouping.

The organization methods of cooperative learning can be roughly divided into role-play, debate and patching method, etc.. Role-play means that each participant receives and plays a character to increase its own 
responsibility. Debate includes intra-group and inter-group forms, which would increase their critical thinking. Patching method also known as experts learning, each member is required to learn diverse knowledge in different group and pass to others. The goal of cooperative learning can only be achieved if all the points are in their hand. According to learning content and learning condition, the role-play is adopted in the back of the case design.

\section{Cooperative Learning Activity Process Model in the Future Classroom}

In this paper, we have analyzed the elements of cooperative learning activity which include cooperation, collaboration object (learning objectives), the cooperative community, collaboration rules and collaboration division of tasks, and learning support. Proceeding from cooperation, future classroom where the learning cooperation could obtain the effective space and technical assistance has advantages that it can work well for the process of learning cooperative activities to form team interdependence, keep the outcomes clear, draw learning content, and bring forward assessment and re-thought, as shown in Figure 2

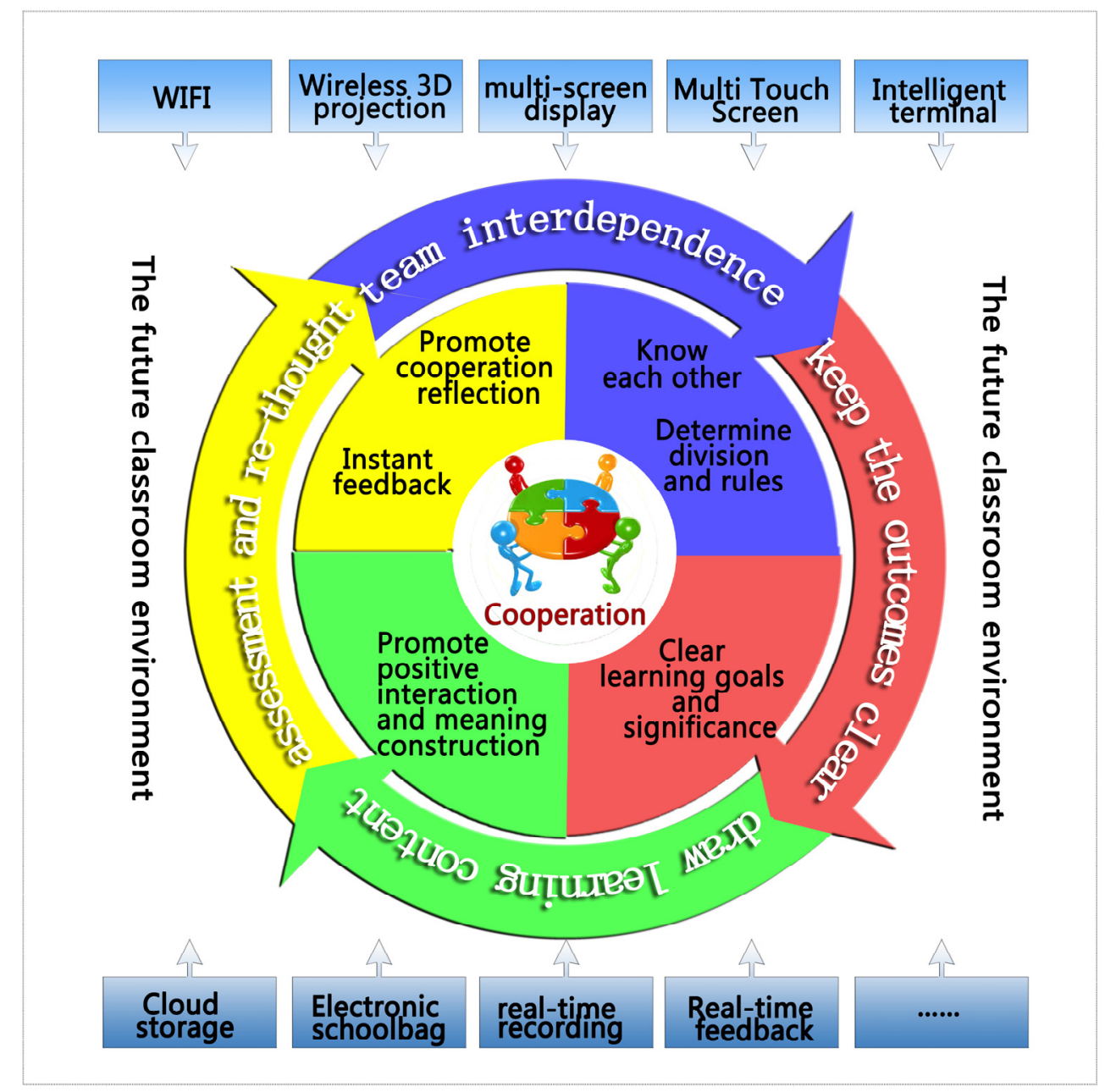

Figure 2. The process of cooperative learning activities in the future classroom environment

As shown in Figure 2, the supports embodies in every link of the process of cooperative learning activity. 


\section{Form Team Interdependence}

In this link, the future classroom which is a barrier-free learning space that tables and chairs are flexible can promote team members to know each other and discuss cooperation rules, and at the same time, optimize the task distribution according to the different characteristics of the members.

\section{Keep the Outcomes Clear}

In this link, the technology of multi-display in future classroom makes exposition of the learning objectives more clear that knowledge objective and cooperative target by teacher are easily understand for students. Furthermore, another technology, intelligent terminal, can capture the interest of students to explain the learning goals and make students comprehend the connection of the learning goals and actual life.

\section{Draw Learning Content}

In this link, using the technologies of wireless network coverage, mobile terminal, and multi-display, future classroom lay a solider foundation to interaction and effectively promote group interaction, interaction between the groups, groups and teachers interactions, interaction between the groups and media, and interaction between teachers and the medium. In addition, students can gather abundant learning resources through the platform of future classroom which gets course information from multi-media multi-angles and multi-media, and carry out effective learning. "Soft partition" can provide a learning space to help students discuss problem and construct knowledge. Teachers direct and monitor immediately with the help of live video, which could effectively promote significance of learners' knowledge construction.

\section{Bring Forward Assessment and Re-thought}

In this part, the feedback system of future classroom can improve the accuracy and efficiency of group evaluation, mutual evaluation, and teachers' evaluation. Besides, intelligent records and broadcasts system can also provide supervision and observation learning to further promote reflection.

\section{Conclusion and Prospect}

As a new kind of class organizing form, cooperative learning has been attracted more and more researchers. Combining with the advanced technology environment of future classroom, it gave forth more attractive: Support of rich media environment reduces the student learning helplessness. Group dynamics reduces the loneliness of the learners. Process and reflection are valued, which could accelerate the development of students' competence. Highly interactive space promotes the participation of students. Study follow-up system in favor of teachers' instruction and supervision. However, cooperation is an important but not the only organizational model of learning in future classroom and the real class should integrate a variety of form. This paper expected to contribute the one's pygmy effort for related design. To sum up, learning activity of future classroom need to be further explored and studied.

\section{References}

Apple Classroom of Tomorrow (ACOT). (2013). Retrieved from http://ali.apple.com/acot2/program.shtml

Chen, W. D. (2011). Research on the future classroom from the perspective of educational technology. Shanghai: East China Normal University.

Chen, W. D., \& Zhang, J. P. (2010). The future orientation and characteristics of classroom. Journal of Electrochemical Education Research, 7, 23-28.

Chen, W. D., Ye, X. D., Qin, J. Y., \& Zhang, J. P. (2011). The next class-Highly interactive learning space. China Audio-Visual Education, 8, 6-13. 
Chen, X. M. ( 2003). Group cooperative learning organization construction. Journal of Education Scientific Research, 2, 5-8.

Christensen, C. M., Horn, M. B., \& Johnson, C. W. (2008). Disrupting class: How disruptive innovation will change the way the world learns. New York: McGraw-Hill.

Cui, Q. S., \& Xie, J. G. (2009). Into the Du Lang mouth autonomous learning teaching pattern. Beijing: China Forestry Publishing House.

David, W. J . (2004). Cooperative learning. Beijing: Beijing Normal University Press.

Ellis, A. K. (2005). Research on educational innovations. Princeton Junction, N.J.: Eye on Education.

Engeström. (2001). Expansive learning at work: Toward an activity theoretical reconceptualization. Journal of Education and Work, 14(1), 133-156.

Gao, D. D. (2012). Classroom teaching structure to explore the future. Journal of Modern Distance Education, 2, 54-60.

Gao, D. D., Chen, X. D., \& Zhang, J. P. (2009). The design of the future classroom. China Audio-visual Education, 11, 11-15.

Jiang, L. (2009). The factors influencing cooperative learning implementation analysis. Journal of the New Curriculum Research, $11,95-99$.

Johnson, D. W., Johnson, R. T., \& Stanne, M. B. (2000). Cooperative learning methods: A meta-analysis. Retrieved from http://www.ccsstl.com/sites/default/files/Cooperative\%20Learning\%20Research\%20.pdf

Massachusetts Institute of Technology (MIT). (2013). Technology enabled active learning. Retrieved from http://icampus.mit.edu/projects/teal/

Sheng, Q. L. (2006). Cooperative learning design. Zhejiang: Zhejiang Education Press.

Wang, M., \& Zhong, Z. X. (2008). Theory of promoting knowledge construction of learning environment design. Open Education Research, 4, 22-27.

Wang, T. (2002). Basic idea of cooperative learning theory. Journal of Education Research, 2, 68-72.

Xu, Y. F., \& Zhang, J. P. (2013). Experience learning oriented future classroom design, based on the improved framework of PST. China Audio-Visual Education, 4, 13-19.

Xu, Y. F., Wang, Z. X., \& Ma, J. (2013). Based on the design and application experience of learning for the future of the classroom. Journal of Electrochemical Education Research, 5, 73-79.

Xu, Y. F., Ye, X. D., \& Wang, Q. (2013). Design framework of the future classroom study. Journal of Distance Education, 4, 83-91.

Yang, K. C. (2005). Learning activities centered teaching design theory, theory of teaching design new exploration. Beijing: Electronic Industry Press.

Zhang, J. P., \& Chen, W. D. (2010). The main position of teaching: The future classroom study. Journal of Modern Education Technology, 10, 44-50. 